\title{
Analysis of Financial Risks in the Process of Enterprise M\&A-Taking Alibaba M\&A Process as an Example
}

\author{
Weizheng Fang ${ }^{1, \dagger}$, Boting Tao ${ }^{2, \dagger}$, Jixian Zhang ${ }^{3, \dagger}$, Linshan Zhao ${ }^{4, *, \dagger}$ \\ ${ }^{1}$ Nottingham University Business School (China), University of Nottingham Ningbo China, Ningbo, China, 315100 \\ ${ }^{2}$ Princeton High School \\ ${ }^{3}$ international business college, South China Normal University, Foshan, China, 528000 \\ ${ }^{4}$ University of Connecticut \\ ${ }^{*}$ Corresponding author. Email:linshan.zhao@uconn.edu \\ ${ }^{\dagger}$ These authors contributed equally.
}

\begin{abstract}
With the rapid development of modern enterprises in Internet, more and more enterprises begun to buy other smaller businesses to help the development of their industries. Such action can bring benefit to these enterprises in some way. In this paper, we study the history of Alibaba and analyze Alibaba's financial affairs, such as current assets ratio, net assets, and debt ratio waiting, by listing the advantages and disadvantages of those mergers and give some opinions or suggestions to help to improve the performance of Alibaba. For instance, one of the advantages of Alibaba's Mergers and Acquisitions (M\&A) is that the payback after the high risks is huge, and one of the disadvantages is Alibaba has to pay more money and attention to their new businesses. The company gross profit margin of Alibaba company has decreased throughout the interest. This trend is also caused by the merger strategy in some way. In the end, we hope our study might benefit the enterprise and help the enterprise to develop better and better.
\end{abstract}

Keywords: Mergers and Acquisitions, Financial Analysis, Current Assets, Net Assets.

\section{INTRODUCTION}

Theories related to the financial analysis were originated early and were first used in the United States banking industry. To reduce the risk of lending, financial analysis is used to evaluate debt repayment. As early as the early 20th century, the world-famous Wall Score was proposed by Alexander Wole [1]. It mainly uses some ratio indicators to evaluate enterprises' credit status and reduce the credit risk of banks. George Foster [2] classified the financial analysis as ratio analysis, horizontal and vertical comparative analysis, empirical analysis, etc., making it more convenient for later generations to apply. Erich A. Helfert and Balic L [3]built a new financial analysis system from the four dimensions of business operating-investment-fundraising and value assessment, linking business activities, investment decisions, fund-raising activities, and corporate value with traditional financial statement analysis.

In addition, many people supported mergers and acquisitions. Research by scholars represented by Weston shows that obtaining synergy is an important aspect of corporate mergers and acquisitions. Through mergers and acquisitions, companies can reduce financing costs, improve operational efficiency, and give a full play to the synergies [4]. Vojislav and Gordon [5]pointed out through research that the motivations of corporate mergers and acquisitions could be considered from the perspectives of the public sector and the private sector. The former is to achieve expansion and obtain resources, while the latter is to achieve synergy and improve efficiency [6]. Also, Hailong Yan proposed the synergy theory that corporate mergers and acquisitions are beneficial to the whole society, which is mainly reflected in the efficiency improvement under the synerg [7]. Gehrig t. [8], throughout the study, thought that mergers and acquisitions company need a large stake in mergers and acquisitions company. In this way, the success rate will be increased, and mergers and acquisitions company, if not hold the stock of the target company, also need to master a large number of mergers and acquisitions company money, all of which are for m\&a companies to have a positive impact, If the acquirer wanted to buy a large stake in the target company, he would surely have legal and ethical constraints. Foad $\mathrm{H}$, Lundberg C. [9]pointed out that the early stage of the 
development will also have an impact on the target company in order to interact with the specific positions of the target company. In today's legal era, legal entities must own more than a certain percentage of information that is relevant to their interests. However, full disclosure must be made upon request. Therefore, it is necessary to use this method to gain revenue, which is not an easy thing to do.

Fitzpatrick [10] collected and classified the financial data of 19 companies according to the fact whether they were bankrupt or not and analyzed the financial data of each classified company. He believed that the current financial risk of a company, especially a company with continuous loss, was mainly determined by the rate of return on capital. And bond equity ratio can also be reflected.

Beaver [11] used the 30 financial indicators of 79 groups of companies in the market as research targets and performed detailed calculations. Through comparison, they found that there were obvious differences between the financial ratios of each company. Based on the experimental data, they constructed a financial risk evaluation model.

Blum [12] classified the financial data of 115 companies according to the fact whether they were bankrupt or not, as a research sample, and considered cash flow factors in financial data analysis. The financial risk analysis model construction included financial indicators that reflected the cash flow and included them after the financial indicators related to cash flow, he found that the forecast period of financial risk prediction models had been expanded. He believes that cash flow played a vital role in the impact of corporate financial risks [13].

Edward. Altman [14]first constructed a Z-Score model based on multivariate early warning. He selected 66 U.S. manufacturing companies that had been bankrupt for 10 years as the research sample to make statistics. It involved 22 corporate financial indicators. A multivariate early warning model was analyzed and established from five analysis angles. And from these perspectives, the five variables have been identified as discriminant variables. The final result showed that this multivariate early warning model could relatively accurately evaluate the short-term risks of enterprises and the risk and the $\mathrm{Z}$ value showed a certain inverse proportional relationship [15].

British scholars Feng Yu Lin and Sally Mc Clean [16] combined discriminant analysis method, logistic regression method, neural network method and decision tree method to establish a hybrid model. Studies have proved that under the same conditions, the prediction results of the mixed model are more accurate than the single model [13].
Mariekede [13] constructed a cash flow model and introduced cash flow into the early warning study of corporate financial risks [14].

Matthieu [17]took the relevant financial data of 32 companies with high financial risk as the research object, and designed an early warning multivariable logic model based on the Logistic model. After validation, it is found that the early warning multivariable logic model could predict corporate financial crisis in almost any situation.

When Beaver [18] selected a single variable to analyze the financial status of a company for the first time, he found that the ratio of net profit to total assets and the ratio of working capital to current liabilities could effectively identify the financial status.

Ohlson [19] proposed that a company's financial risk status and failure risk can be predicted by four indicators: company capital structure, production scale, operating efficiency, and capital liquidity.

In the following sections, we will analyse Alibaba.

\section{METHOD}

In this article, we will detail the financial risk analysis in the process of Alibaba's merger and acquisition. In the analysis process, we use scientific methods such as literature research, comparative analysis, quantitative analysis, and case analysis. The methods are mainly described in the following:

The method of literature research: Such a method is a kind of scientific research method of consulting literature and information in a purposeful and planned way around the needs of research projects and topics. It is a basic method that must be used to complete the task of scientific research.

Comparative analysis method: It is to compare objective things in order to understand the nature and laws of things and make correct evaluations. This method usually compares two interrelated index data to show and explain the size of the research object, the level of the research object, the speed of the speed, and whether the various relationships are coordinated.

Quantitative analysis method: It is the analysis of the company's quantifiable data by investment analysts using mathematical modules and evaluates the company's operations and makes investment judgments through the analysis. The objects of quantitative analysis are mainly financial statements, such as capital balance sheet, income statement, retained income statement, etc.

Case analysis method: The case analysis method is also the typical analysis method. It is a scientific analysis method that conducts thorough and careful research on representative things or phenomena to obtain an overall understanding. 
According to the above methods, this article first investigates the relevant references of corporate mergers and acquisitions, and on the basis of a large amount of theoretical knowledge, conducts research on financial risks in the process of corporate mergers and acquisitions, selects a typical representative of the Internet industry Alibaba, collects related financial statement data of Alibaba, analyses the collected data, discover the financial risks, and finally analyze the causes of the risks and give more reasonable strategies or suggestions.

\section{RESULTS AND DISCUSSION}

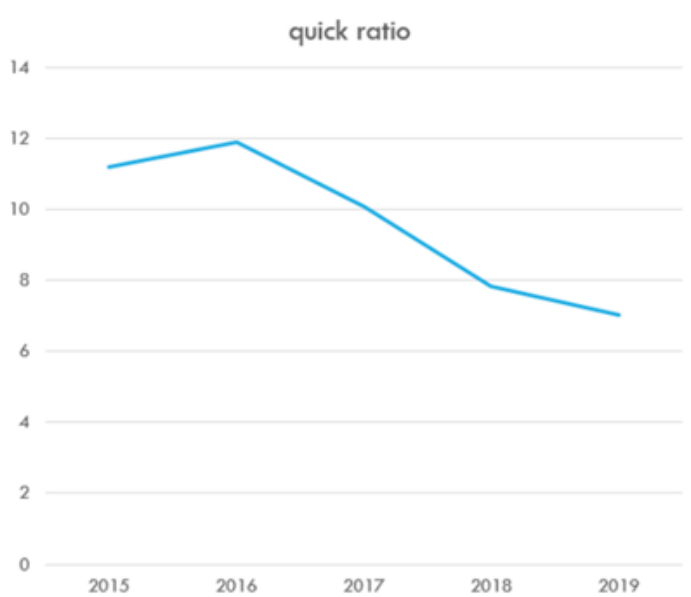

Figure 1. Quick ratio of Alibaba

According to this figure, the quick ratio of Alibaba group shows a declining trend during 2015-2019. Quick ratio is equal (cash +accounts receivable)/current liabilities. The quick ratio of Alibaba group decreases from 11.88 in 2016 to 7.04 in 2019, it was a huge decline, which means the growth of liabilities is much faster than the assets. This situation also reflects the Alibaba group was in involve the problem of low liquidity. First of all, the company's merger strategy leads to the liabilities arising. In 2016, Alibaba group accomplish the acquisition of Youku and Tudou, at the same time, it spent 1.25 billion on investing elm. In the years that followed, it had completed the wholly owned -acquisition of DaMai (in 2017), CPU IP core (in 2018), and data Artisans (in 2019). The above-mentioned content is only a little part of Alibaba 's merger strategy, such a huge merger would inevitably lead to an increase in the company's debt, thus affecting the quick ratio of Alibaba group.

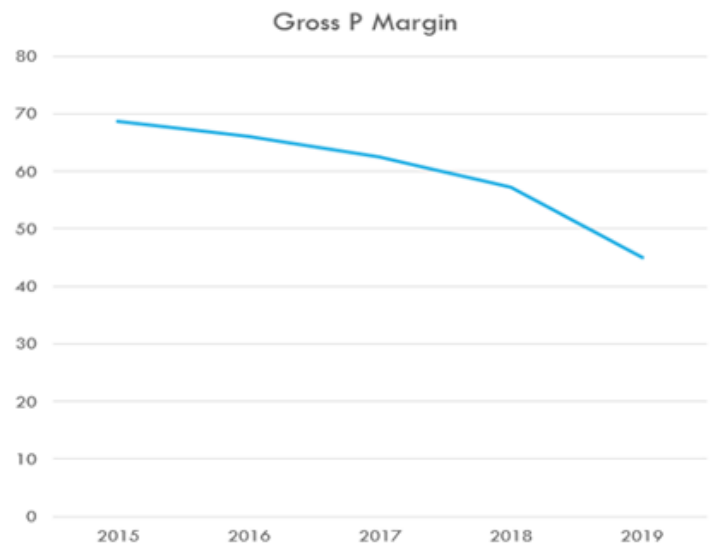

Figure 2. Gross Profit Margins

Gross profit has been reducing since 2015, its ratio to the revenue expressed as a percentage. It is affected by the cost of goods which reduces gross profit, can be attributed to increased taxation on the goods sold online and indicate whether or not the business is still healthy. Profit $=$ total revenue-total expenditure, expenditure includes money spent on mergers and acquisitions. Alibaba was hit by Pinduoduo and JD.com, resulting in little increase in revenue. At the same time, mergers and acquisitions occupy a certain amount of cost, leading to a decline in profits.

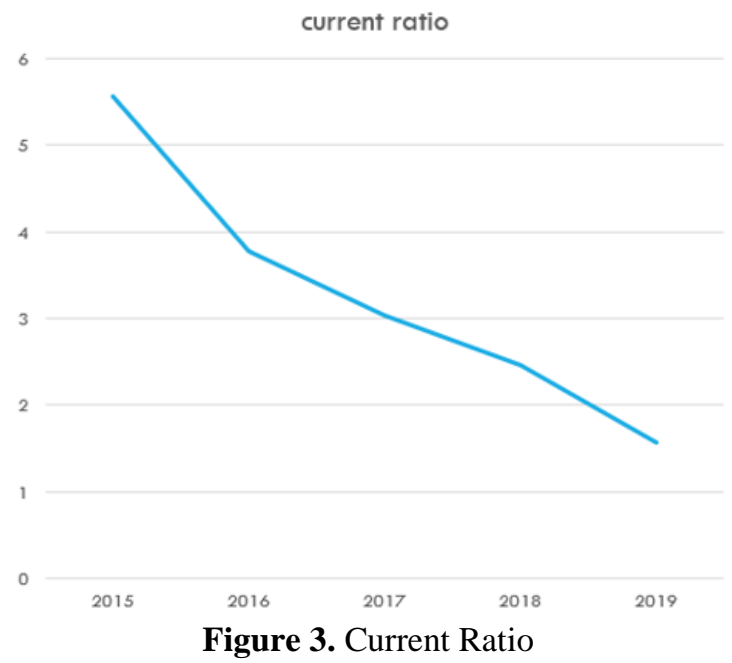

The current ratio of Alibaba has been reducing over the period of interest. Still, it indicates that the business is creditworthy as the current assets are higher than the current liabilities and the company can use its current assets to pay off current liabilities. This is also caused by the merger strategy. 


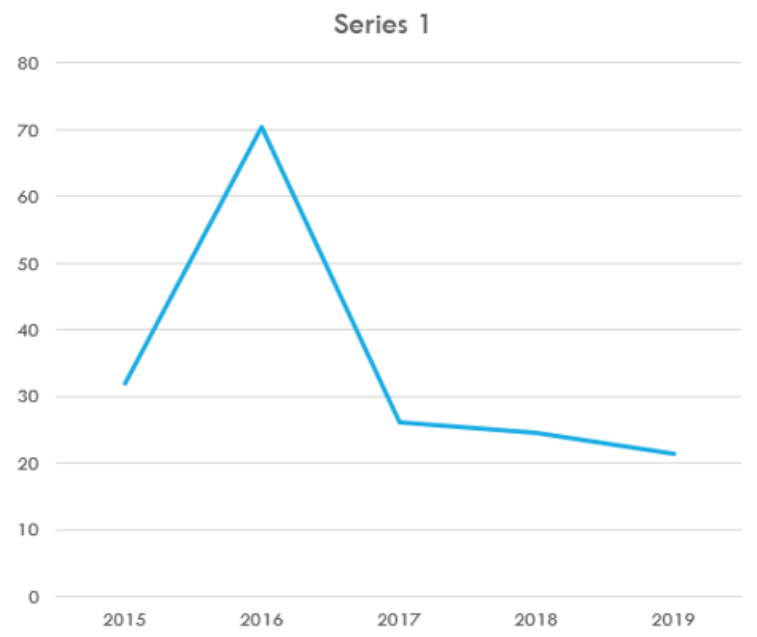

Figure 4.Net Profit Margins

Net profit margin is a ratio of the net profit to revenue generated expressed as a percentage. It shows the company is performing well and profitably. Cost of doing business example taxes and cost of goods lead the trend.

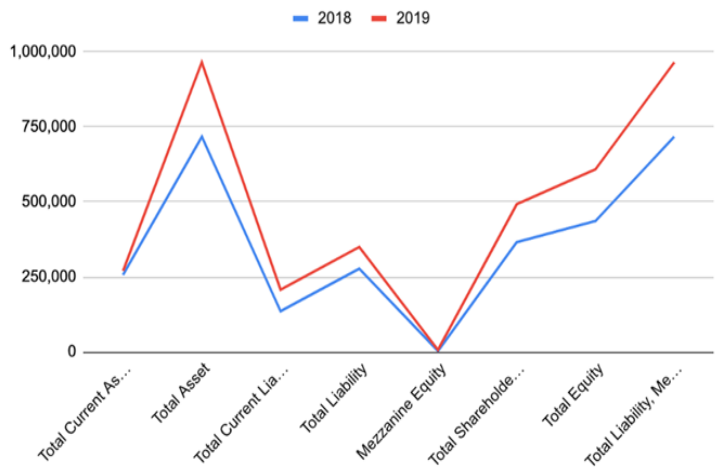

Figure 5. Balance Sheet of Alibaba from 2018-2019
According to the balance sheet, it is obvious that the total assets, liability and equity in 2018 are less than 2019.

The reason that the total assets in 2019 are higher is the values of Total current assets, Investment securities, Prepayments, Receivables, and other assets, Property and equipment, Intangible assets and Goodwill in 2019 are higher than the ones in 2018. For example, the total current asset of 2019 is $5.22 \%$ higher than 2018 $((270,273-256,855) / 256,855 * 100 \approx 5.22 \%)$, and the investment securities of 2019 is $311.32 \%$ higher than $2018((157,090-38,192) / 38,192 * 100 \approx 311.32 \%)$.

The total liability in 2019 is higher is because the values of Total current liabilities, Deferred revenue, Deferred tax liabilities, Non-current bank borrowings and Other liabilities in 2019 are higher than 2018. For instance, the total current liabilities of 2019 are $52.91 \%$ higher than $2018((207,669-135,810) / 135,810 * 100 \approx$ $52.91 \%$ ), and the deferred tax liabilities of 2019 is $16.6 \%$ higher than $2018((22,517-19,312) / 19,312 * 100 \approx$ $16.6 \%)$.

The reason that the total equity in 2019 is higher is the values of Mezzanine equity, Total shareholders' equity, and Noncontrolling interests in 2019 are higher than the ones in 2018. For instance, the mezzanine equity of 2019 is $127.22 \%$ higher than $2018((6,819-3,001) /$ $3,001 * 100 \approx 127.22 \%$ ).

According to the line graph and the table in this paper, we could see that the total assets and liability of Amazon are higher than Alibaba, but the total equity of Alibaba is higher than Amazon. A higher value of assets means Amazon earned more money than Alibaba by using it's

Table 1. Table of Balance Sheet of Amazon and Alibaba in 2019 (in USD million)

\begin{tabular}{|l|l|l|l|l|l|l|}
\hline Year :2019 & $\begin{array}{l}\text { Total } \\
\text { Current } \\
\text { Assets }\end{array}$ & Total Assets & $\begin{array}{l}\text { Total Current } \\
\text { Liabilities }\end{array}$ & $\begin{array}{l}\text { Total } \\
\text { Liabilities }\end{array}$ & $\begin{array}{l}\text { Total } \\
\text { Shareholders' } \\
\text { Equity }\end{array}$ & Total Equity \\
\hline Amazon & 96,334 & 225,248 & 87,812 & 163,188 & 62,060 & 62,060 \\
\hline Alibaba & 40,272 & 143,801 & 30,944 & 52,104 & 73,348 & 90,681 \\
\hline $\begin{array}{l}\text { Difference } \\
\text { Amazon } \\
\begin{array}{l}\text { Percentage } \\
\text { decrease } \\
\text { Alibaba }\end{array}\end{array}$ & $\begin{array}{l}56,062 \\
\text { increased }\end{array}$ & 81,447 & 56,868 & 111,084 & 11,288 & 28,621 \\
& increased & $\begin{array}{l}64.76 \% \\
\text { increased }\end{array}$ & $\begin{array}{l}68.97 \% \\
\text { increased }\end{array}$ & $\begin{array}{l}18.19 \% \\
\text { decreased }\end{array}$ & $\begin{array}{l}46.12 \% \\
\text { decreased }\end{array}$ \\
\hline
\end{tabular}


strategies, and a higher value of liability means that Amazon spent more money than Alibaba. However, Alibaba has a higher value of shareholder's equity, which shows that Alibaba is more valuable than Amazon. Although Amazon spent more money to acquire more small businesses than Alibaba and earned much money, Alibaba this company is still much valuable than Amazon, which indicates that Alibaba's strategy of mergers and acquisitions is better than Amazon's.

\section{CONCLUSIONS}

Our suggestion that helps Alibaba to get better is to be innovative. Because the commonality of enterprises is to provide services to their consumers, each corporate culture has certain similarity, and its cultural value concept is essentially the same. If Alibaba can make their culture unique, then it will obtain more consumers. Enterprises should consider the final risk when they merge.

This article analyses the financial issues in the process of Alibaba's mergers and acquisitions, analyses what methods can help Alibaba, and uses Alibaba's balance sheet to analyse the impact of mergers and acquisitions on Alibaba. At the end, we also give some suggestions to help Alibaba become better.

\section{REFERENCES}

[1] Duning, William R. Ratio analysis of financial statements [M]. Harper \& Brothers, 1928.

[2] Foster, George. Asset Pricing Models: Further Tests. Journal of Financial and Quantitative Analysis, vol. 13, 1978, pp39-53.

[3] Erich A. Helfert and Balic L, Techniques of financial analysis : a modern approach, 1997.

[4] Yiming Li, Research on motivation and performance of Merger and acquisition of Eleme by Alibaba. 2013.

[5] Maksimovic, V., \& Phillips, G. C. Conglomerate Firms, Internal Capital Markets, and the Theory of the Firm. Annual Review of Financial Economics, vol. 5, 2013, pp:225-244.

[6] Dong Han, Case Study on the Integration Risk of the Merger of Eleme By Alibaba. 2020.

[7] Shuwen Huang, Analysis on the Causes and Performance of Alibaba's Acquisition of Youku Tudou. 2020.

[8] L. Williamson, D. Griffin, J. Elmer, T. Gehrig, S. Haccou FACILITATING DOCTORAL BUSINESS STUDENT SUCCESS: AN EXAMINATION OF BLACKBOARD COMMUNITY SHELL
EFFECTIVENESS. EDULEARN18 Proceedings, 2018, pp:313-317.

[9] Foad, H., \& Lundberg, C. The Determinant of Portfolio Investment in Offshore Financial Centers. International Review of Financial Analysis, vol.54, 2017, pp:76-86.

[10] Fitzpatrick, P. J. A Comparison of Ratios of Successful Industrial Enterprises with Those of Failed Firms. Washington: Certified Public Accountant, 1932, pp:656-662.

[11] Beaver.Financial Ratios as Predictors of Failures in Empirical Research in Accounting [J].AccountingResearch,1967. pp:342-343.

[12] Blum, M. Failing Company Discriminant Analysis. Journal of Accounting Research, vol. 12, 2004, pp1-25.

[13] Mariekede G.Repoliticizing financial risk[J].Economy of Amsterdam ,vol. 33, 2004 pp:29-34.

[14] Altman, H. FINANCIAL RATIOS DISCRIMINANTS, ANALYSIS AND THE PREDICTION OF CORPORATE BANKRUPTCY. Journal of Finance,vol. 23, pp589-609.

[15] Yulin, F. \& Sally, M. A data mining approach to the prediction of corporate failure [J]Knowledge-Based Systems, vol.6, 2011, pp:189 195.

[16] Feng Y L, Mcclean S I . THE PREDICTION OF FINANCIAL DISTRESS USING STRUCTURED FINANCIAL DATA FROM THE INTERNET. 2000.

[17] Matthieu Bussiere, Marcel Fratzscher. Towards A New Early Warning System of Financial Crises[J].European Central Bank, ,vol.6, 2008, pp:8.

[18] Beaver W H. Financial ratios as predictors of failure[J].Journal of Accounting Research,vol. 41, 1966, pp:71 111 .

[19] Ohlson J A.Financial ratios and the probabilistic prediction of bankruptcy[J]. Journal of AccountingResearch, vol.18, 1980, pp:109 131. 